2014

\title{
Quantitative Reasoning Learning Progression: The Matrix
}

\author{
Robert L. Mayes \\ Georgia Southern University, rmayes@georgiasouthern.edu \\ Jennifer Forrester \\ University of Wyoming, jforres5@uwyo.edu \\ Jennifer Schuttlefield Christus \\ University of Wisconsin - Oshkosh, schuttlj@uwosh.edu \\ Franziska Peterson \\ University of Wyoming, fpeterso@uwyo.edu \\ Rachel Walker \\ Georgia Southern University, rw01319@georgiasouthern.edu
}

Follow this and additional works at: https://digitalcommons.usf.edu/numeracy

Part of the Science and Mathematics Education Commons

\section{Recommended Citation}

Mayes, Robert L., Jennifer Forrester, Jennifer Schuttlefield Christus, Franziska Peterson, and Rachel Walker. "Quantitative Reasoning Learning Progression: The Matrix." Numeracy 7, Iss. 2 (2014): Article 5. DOI: http://dx.doi.org/10.5038/1936-4660.7.2.5 


\title{
Quantitative Reasoning Learning Progression: The Matrix
}

\begin{abstract}
The NSF Pathways Project studied the development of environmental literacy in students from grades six through high school. Learning progressions for environmental literacy were developed to explicate the trajectory of learning. The Pathways QR research team supported this effort by studying the role of quantitative reasoning (QR) as a support or barrier to developing environmental literacy. An iterative research methodology was employed which included targeted student interviews to establish QR learning progression progress variables and elements comprising those progress variables, development of a QR learning progression framework, and closed-form QR assessments to verify the progression. In this paper the focus is on development of the current iteration of the QR learning progression, including a brief discussion of the first and second iterations that provide a look into the development of a learning progression. The focus is on the latest iteration, with a detailed discussion of the progress variables: Quantitative Act (QA), Quantitative Interpretation (QI), and Quantitative Modeling (QM). The elements that constitute these progress variables which arose from our analysis of qualitative interview data and quantitative assessment data are provided. Discussion of the evolution of the QR assessment to document students' abilities to utilize the progress variables occurs concurrently with explanation of the learning progression development. The most recent QR assessment focused on QI. The data from this assessment will provide additional information to revise the learning progression QI progress variable. A similar effort is planned for the QA and QM progress variables.
\end{abstract}

\section{Keywords}

quantitative reasoning, quantification, quantitative literacy, modeling, learning progression, environmental literacy

\section{Creative Commons License}

This work is licensed under a Creative Commons Attribution-Noncommercial 4.0 License

\section{Cover Page Footnote}

Robert Mayes is a Research Professor in Education at Georgia Southern University, United States, and Director of the Institute for Interdisciplinary STEM Education (i2 STEMe). His research focus is on systems reasoning, computational reasoning, and quantitative reasoning in STEM and development of reasoning learning progressions within the context of science. His work supports interdisciplinary STEM teaching that impacts underrepresented populations and rural areas.

Jennifer Harris Forrester is an Assistant Professor in Elementary and Early Childhood Education at the University of Wyoming. Her research focuses on the use of quantitative reasoning skills in different science contents and contexts. She is interested in documenting how professional scientists use QR skills in their research (specifically field ecology) and how they teach students QR within the context of fieldwork. Her work supports best practices in STEM teaching at the K-12 and undergraduate level. Jennifer Schuttlefield Christus is an Assistant Professor of Chemistry at the University of Wisconsin Oshkosh. Her current research focuses on semiconductor photoelectrochemistry, solar energy conversion, atmospheric reactions on clay mineral aerosols and chemical and science education including quantitative reasoning and the development of learning progressions in the context of science. Franzi Peterson is a graduate student at the University of Wyoming. She is working towards her Ph.D. in Mathematics Education. She has served as the research graduate student on the Pathways Project over the past five years.

Rachel Walker is a graduate student at Georgia Southern University. She is working towards her Master of 
Arts in Teaching with a concentration in Secondary Mathematics.

This article is available in Numeracy: https://digitalcommons.usf.edu/numeracy/vol7/iss2/art5 


\section{Introduction}

In a previous Numeracy article, Mayes et al. (2013a) presented a framework for a learning progression for quantitative reasoning (QR). The framework was extensively grounded in the literature on QR, including the seminal work done by the American Association of Colleges and Universities (AAC\&U 2010), Madison and Steen (2003), and Steen (2001). We refer the reader to this prior paper for the detailed literature review. In this paper we present the iterative research process which brought us to the current version of the QR learning progression by briefly discussing the first two iterations of the progression. We then explain the intricacies of the current progression and preface the next stage of development. We will provide the reasoning behind the selection of three progress variables in the current iteration of the QR learning progression: Quantification Act (QA), Quantitative Interpretation (QI), and Quantitative Modeling (QM). QA, QI, and QM will be explicated through a detailed discussion of elements that constitute the progress variables.

The QR learning progression was developed as part of the NSF project, Culturally Relevant Ecology, Learning Progressions, and Environmental Literacy $^{1}$ (which we refer to simply as Pathways). Pathways primary outcomes were the development of learning progressions that provide a trajectory along which middle and high school students become environmentally literate citizens. The Pathways Quantitative Reasoning Team focused on the role of QR in students' development of environmental literacy. The QR team supported the three Pathways Science Strand Teams, which consisted of a Biodiversity Strand, a Carbon Strand, and a Water Strand in development of learning progressions. The development of the learning progression included the creation of student interviews, closed-form assessments, and teaching experiments supporting the study and implementation of the progressions. The QR team determined through these support efforts that there was a need for a QR learning progression in science.

The Consortium for Policy Research in Education ${ }^{2}$ (CPRE) defines a learning progression as a set of "empirically grounded and testable hypotheses about how students' understanding of, and ability to use, core scientific concepts and explanations and related scientific practices grow and become more sophisticated over time, with appropriate instruction” (Corcoran et al. 2009, p. 8). Learning progressions have been identified as a promising model for advancing effective

\footnotetext{
${ }^{1}$ Award number 0832173. Program: MSP Targeted Awards. Division of Research on Learning in Formal and Informal Settings.

${ }^{2}$ http://www.cpre.org/ (all links in the footnotes were accessed May 9, 2014).
} 
adaptive-instruction teaching techniques thereby changing the norms of practice in schools (Corcoran et al. 2009). Duschl et al. (2007) recommend that learning and curriculum designs be organized around learning progressions as a means of supporting learners' development toward attaining four proficiencies in science, which they identify as: (1) know, use and interpret scientific explanations of the natural world; (2) generate and evaluate scientific evidence and explanations; (3) understand the nature and development of scientific knowledge; and (4) participate productively in scientific practices and discourse. The QR team hypothesizes that QR is essential for data-based and model-based reasoning approaches to learning science which are embedded in the Next Generation Science Standards ${ }^{3}$ (NGSS) and promoted by the Common Core State Standards for Mathematics ${ }^{4}$ (CCSS-M).

The previous Numeracy article (Mayes et al. 2013a) provides a detailed exposition on how we arrived at a definition of QR and established a framework that included the current three progress variables of QA, QI, and QM and the additional variable of Quantitative Literacy (QL) (see Fig. 1).

Definition of QR in Context: Quantitative Reasoning in Context (QRC) is mathematics and statistics applied in real-life, authentic situations that impact an individual's life as a constructive, concerned, and reflective citizen. QRC problems are context-dependent, interdisciplinary, open-ended tasks that require critical thinking and the capacity to communicate a course of action.

QR Framework: We initially proposed a quantitative reasoning framework that had four progress variables: 1. Quantification Act (QA): Mathematical process of conceptualizing an object and an attribute of it so that the attribute has a unit measure.

2. Quantitative Literacy (QL): Use of fundamental mathematical concepts in sophisticated ways for the purpose of describing, comparing, manipulating, and drawing conclusions from variables developed in the quantification act.

3. Quantitative Interpretation (QI): Ability to use models to discover trends and make predictions.

4. Quantitative Modeling (QM): Ability to create representations to explain a phenomenon and to revise them based on fit to reality.

Hypothesized interaction of the progress variables when addressing a science problem in context.

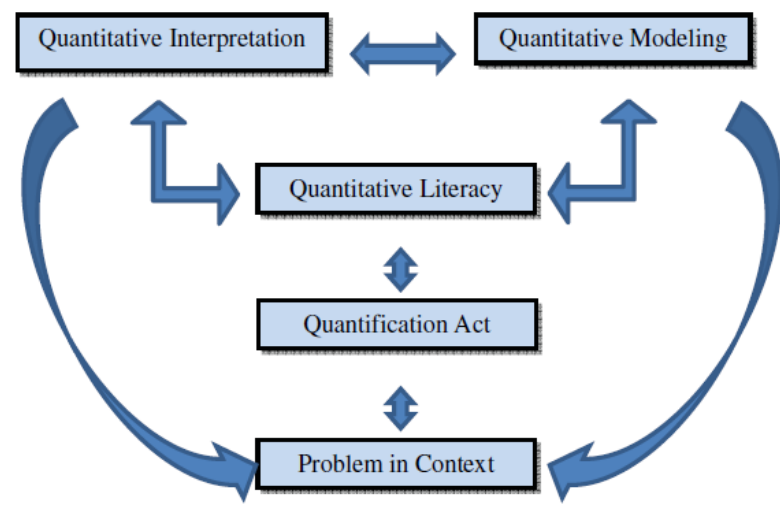

Figure 1. Summary of QR framework from Mayes et al. (2013a)

\footnotetext{
${ }^{3}$ http://www.nextgenscience.org/

4 http://www.corestandards.org/Math/
} 
The framework from Mayes et al. (2013a) was based on an intense review of the literature on quantitative reasoning, extensive work with science and mathematics teachers through a professional development project called QR STEM, and informed by interviews of students from grades 6 through 12. Each of the original hypothesized progress variables were elucidated through identifying a collection of elements that were considered fundamental to them:

- Quantification Act (QA) included the elements of variable identification, communication, context, and variation.

- Quantitative Literacy (QL) included the elements of numeracy, measurement, proportional reasoning, and basic probability and statistics.

- Quantitative Interpretation (QI) included the elements of representations, science diagrams, statistics and probability, and logarithmic scales.

- Quantitative Modeling (QM) included the elements of logic, problem solving, modeling, and inference.

\section{QR Learning Progression: First Iteration}

The first stage in developing a QR learning progression was to move from the QR framework of Mayes et al. (2013a) to a trajectory of QR development including achievement levels. Achievement Levels (AL) are steps through which students transit as they develop increasing mastery of a concept. The first iteration of the QR learning progression included the four progress variables QA, QL, QI and QM, each with four achievement levels: AL1, called the lower anchor, is what is known about students' reasoning in specific concepts when entering the $6^{\text {th }}$ grade; AL4, called the upper anchor, is defined as the expectations society has about students' knowledge and understanding when they finish high school; AL2 and AL3 are transitional levels from AL1 to AL4. The achievement levels are not a reflection of a student's perceived sophistication based on grade level, but instead current ability.

Within each of the progress variables the elements provide characteristics or properties that allow the student to be classified at a particular achievement level of a given progress variable. An element of QI for example is "Trends" (Fig. 2). Students at AL4 within the Trends element would be able to determine multiple types of trends including linear, power, and exponential trends; as well, they would be able to recognize and provide quantitative explanations of trends in model representations within the context of a problem. Students at AL1 would not be able to determine trends from a table or graph. The QR elements had been 
determined previously (Mayes et al. 2013a), but they were refined through the iterations of the learning progression.

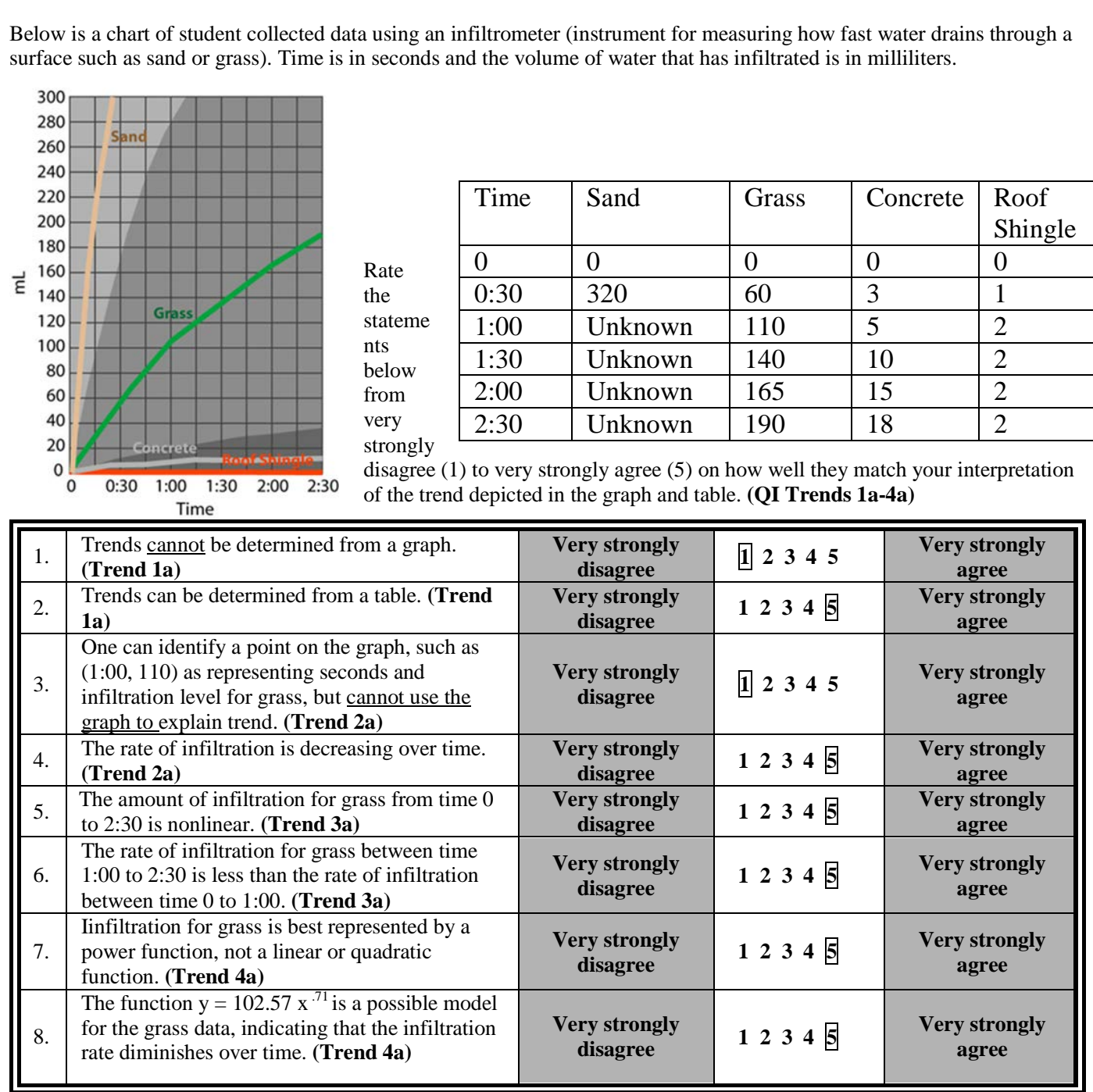

Figure 2. Quantitative Interpretation (QI) closed-form assessment of Trends element for the topic of water cycle. Note the intent of the assessment is not calculation, but understanding of interpreting trends from a table or graph.

The AL1 achievement level represents what we observed in student interviews as entry-level QR ability. AL1 achievement level included avoidance of QR due to many factors, including the inability to identify and quantify variables in a context; resorting to qualitative accounts that ignored quantitative information provided in the problem; inability to apply arithmetic processes to 
compare and combine quantitative data; avoidance of using the model provided to support an interpretation of an environmental problem; and not viewing science as a model-building activity.

AL4 achievement level represented what scientists, science educators, and other QR team experts on the Pathways Project viewed as the abilities an environmentally literate citizen should possess upon graduation from high school. In the initial iteration of the QR learning progression, the number of elements included at AL4 was in the range of seven to eight elements per progress variable.

Some of the elements at AL4 were not defined at AL1 or the AL2 and AL3 intermediate achievement levels, making it difficult to track student ability across achievement levels. A decision was made to reduce the number of elements by combining or eliminating elements based on data collected during Spring 2012 student interviews on QR ability.

An additional design decision was made to reduce the number of progress variables from four to three by embedding QL into the QA progress variable, making QL an element of QA. This decision was based on discussions with national experts in science education and mathematics education. These discussions took place through the Pathways Project, development of the first QR framework Numeracy article, and a national QR Symposium hosted in Savannah, Georgia, in Summer 2012 which brought together national experts on QR and learning progressions. The consensus opinion was that QL, as the Pathways QR team was interpreting it, was more a collection of procedural skills than a central conceptual component of $\mathrm{QR}$, thus it should not be a progress variable in the learning progression. However, the QR team believed that QL was essential to moving from the Quantification Act (QA) to interpreting models (QI) and building them (QM), so QL was folded into QA as an element. QL provides the tools and processes for comparing and combining variables coming out of QA, which, in turn, leads to model building.

\section{QR Learning Progression: Second Iteration}

The task of reducing the number of elements for the remaining three progress variables was undertaken by analyzing student interviews to determine what elements students in grades $6^{\text {th }}$ to $12^{\text {th }}$ grade used and understood when addressing environmental issues. Details of this research were published in the International Journal of Science Education (Mayes et al. 2013b), including a revised learning progression (second iteration LP) with three progress variables defined by fewer and more-relevant elements. Relevance of the elements is determined from interviews of 39 middle and high school science students. No association of student understanding to formal school programs versus informal science 
experiences was attempted. This was not a study of the impact of a given curriculum or program on student environmental literacy.

The interviews were conducted using three QR qualitative assessments developed by the QR team that were based on key conceptual strands in environmental literacy identified by the Pathways science teams: Carbon Cycle, Water Cycle, and Biodiversity. Each QR assessment was organized across three levels of scale: macro-scale (personal experience of the world; what can be seen with the eye), landscape scale (global generalizations; what can be seen with a telescope or larger), and micro/atomic scale (hidden mechanisms; what can be seen with a microscope or smaller). Students were selected by their classroom teachers. The teachers were directed to select students of both moderate and highlevel ability to participate in interviews. No treatment was provided; the intent was to determine current QR ability in students in $6^{\text {th }}$ through $12^{\text {th }}$ grades at schools in the Western United States. The 30-40 minute, semi-structured interviews were conducted in the schools. All 39 interviews were transcribed and coded, then analyzed using a Grounded Theory (Corbin and Strauss 2008; Charmaz 2006) approach. For further detail, refer to Mayes et al. (2013b) as extensive detail is provided in that report of the research. The findings from this research led to another iteration of the learning progression. The focus of the remainder of this paper is on the resulting changes to the QR learning progression.

The second iteration of the QR learning progression reduced the number of elements within each of the three remaining progress variables to five or fewer items at AL4 and AL3 achievement levels (Table 1). However, the second iteration still had elements that were not defined across all achievement levels. The QI element Variable was defined only at AL1 through AL3, and the QA element Interpret was defined only at AL1 and AL2.

The QR team revisited a sample of the student interviews using the second iteration of the learning progression to address the issue of defining elements at all achievement levels, thereby allowing for the tracking of students across all four achievement levels. The re-visitation of the student interviews indicated that students struggled to communicate quantitative accounts of their solution, decision, and course of action within context. Even those who created variables with attributes held a weak conception of measure for the variable. The QR team determined more data were needed to clarify the Variable element, especially with respect to differentiating an AL3 versus an AL4 for this element. The revisitation of student interviews also raised concerns about the Interpret element, which, while fundamental at the lower achievement levels, lacked the depth to extend to the upper achievement levels and overlapped components of the Trends and Predictions elements 
Table 1

QR Learning Progression Iteration 2 - Revised progress variables and elements.

\begin{tabular}{|c|c|c|c|}
\hline \multirow{2}{*}{$\begin{array}{l}\text { Achievement } \\
\text { Level }\end{array}$} & \multicolumn{3}{|c|}{ Progress Variables } \\
\hline & $\begin{array}{c}\text { Quantification Act } \\
\text { (QA) }\end{array}$ & $\begin{array}{c}\text { Quantitative Interpretation } \\
\text { (QI) }\end{array}$ & $\begin{array}{c}\text { Quantitative Modeling } \\
\text { (QM) }\end{array}$ \\
\hline \multirow[t]{5}{*}{$\begin{array}{l}\text { Elements at } \\
\text { all levels } \\
\text { (AL1, AL2, } \\
\text { AL3 and } \\
\text { AL4) }\end{array}$} & $\begin{array}{l}\text { Variation: reasons about } \\
\text { covariation of two or more } \\
\text { variables; comparing, } \\
\text { contrasting, relating } \\
\text { variables in the context of } \\
\text { problem. }\end{array}$ & $\begin{array}{l}\text { Trends: recognizes and } \\
\text { provides quantitative } \\
\text { explanations of trends in model } \\
\text { representation within context of } \\
\text { problem, including linear, } \\
\text { power, exponential trends. }\end{array}$ & $\begin{array}{l}\text { Create model: ability to } \\
\text { create a model representing a } \\
\text { context and trace through } \\
\text { model correctly. }\end{array}$ \\
\hline & $\begin{array}{l}\text { Quantitative literacy: } \\
\text { reasons with quantities to } \\
\text { explain relationships } \\
\text { between variables; } \\
\text { proportional reasoning, } \\
\text { numerical reasoning; extend } \\
\text { to algebraic and higher math } \\
\text { reason. }\end{array}$ & $\begin{array}{l}\text { Predictions: makes predictions } \\
\text { using model with covariation } \\
\text { and provides a quantitative } \\
\text { account which is applied } \\
\text { within context of problem. }\end{array}$ & $\begin{array}{l}\text { Refine model: test and refine } \\
\text { a model for internal } \\
\text { consistency and coherence to } \\
\text { evaluate scientific evidence } \\
\text { and explanations; determine } \\
\text { results; extend model to new } \\
\text { situation. }\end{array}$ \\
\hline & $\begin{array}{l}\text { Context: situative view of } \\
\text { QR within a community of } \\
\text { practice, solves ill-defined } \\
\text { problems in socio-political } \\
\text { contexts using ad-hoc } \\
\text { methods; informal reasoning } \\
\text { within science context. }\end{array}$ & $\begin{array}{l}\text { Translation: translates } \\
\text { between different models, at } \\
\text { least categorically. }\end{array}$ & $\begin{array}{l}\text { Model reasoning: construct } \\
\text { and use models spontaneously } \\
\text { to assist own thinking, predict } \\
\text { behavior in real-world, } \\
\text { generate new questions about } \\
\text { phenomena. }\end{array}$ \\
\hline & $\begin{array}{l}\text { Communication: capacity } \\
\text { to communicate quantitative } \\
\text { account of solution, } \\
\text { decision, course of action } \\
\text { within context. }\end{array}$ & $\begin{array}{l}\text { Revision: revise models } \\
\text { theoretically without data, } \\
\text { evaluate competing models for } \\
\text { possible combination. }\end{array}$ & $\begin{array}{l}\text { Methods: demonstrate ability } \\
\text { to use variety of methods to } \\
\text { construct model within } \\
\text { context; least squares, } \\
\text { linearization, normal } \\
\text { distribution, logarithmic, } \\
\text { logistic growth, multivariate, } \\
\text { simulation models. }\end{array}$ \\
\hline & & $\begin{array}{l}\text { Authority: question model by } \\
\text { challenging quantitative aspects } \\
\text { as estimates or due to } \\
\text { measurement error, especially } \\
\text { when contrasting models. }\end{array}$ & $\begin{array}{l}\text { Statistical: conduct statistical } \\
\text { inference to test hypothesis. }\end{array}$ \\
\hline $\begin{array}{l}\text { Elements at } \\
\text { only levels } \\
\text { AL1, AL2, } \\
\text { and AL3 }\end{array}$ & $\begin{array}{l}\text { Variable: mental construct } \\
\text { for object within context is } \\
\text { identified, conceptualized so } \\
\text { that the object has attributes } \\
\text { that are measurable, uses } \\
\text { variable in context. }\end{array}$ & & \\
\hline $\begin{array}{l}\text { Elements at } \\
\text { only levels } \\
\text { AL1 and AL2 }\end{array}$ & & $\begin{array}{l}\text { Interpret: identify variables in } \\
\text { the model; provide qualitative } \\
\text { account, avoiding quantities; } \\
\text { form correct mental image to } \\
\text { conceive problem; difficulty } \\
\text { with models that embed variable } \\
\text { or have more than two } \\
\text { interrelated variables. }\end{array}$ & \\
\hline
\end{tabular}




\section{QR Learning Progression: Third Iteration}

To further refine the elements within the learning progressions, a second set of structured interviews was conducted the following spring. In this round, 14 middle and high school students were interviewed using revised QR assessments. The new assessments paralleled extensions made in the Pathways Project environmental science strands. Each strand identified two progress variables on which the science learning progressions focused: the Carbon Strand focused on the Carbon Cycle and Carbon Storage; the Water Strand focused on Water Cycle and Water Transport; the Biodiversity Strand focused on Biodiversity Communities and Biodiversity Extinction. The QR team developed parallel quantitative reasoning assessments for each of these science progress variables, while retaining the structure of asking questions across the three QR progress variables (QA, QI and QL) and scale (macro, landscape, and micro/atomic). The analysis of these interviews led to further reduction of the elements for the QR progress variables. The following is a discussion of the reduction of elements from the second iteration to the third and the reasoning behind inclusion of each of the current elements in QA, QI, and QM. The latest version of the QR learning progression is provided in Table 2. The QR learning progression now has only four elements per progress variable and each element can be tracked across all four achievement levels.

Table 2.

QR Learning Progression Iteration 3

\begin{tabular}{|c|c|c|c|}
\hline \multirow[t]{2}{*}{$\begin{array}{l}\text { Achievement } \\
\text { Level }\end{array}$} & \multicolumn{3}{|c|}{ Progress Variable } \\
\hline & Quantification Act (QA) & $\begin{array}{c}\text { Quantitative } \\
\text { Interpretation (QI) }\end{array}$ & $\begin{array}{c}\text { Quantitative } \\
\text { Modeling (QM) }\end{array}$ \\
\hline \multirow[t]{2}{*}{$\begin{array}{l}\text { Level AL4 } \\
\text { Elements } \\
\text { (Upper } \\
\text { Anchor) }\end{array}$} & $\begin{array}{l}\text { 4a Variation: reasons about } \\
\text { covariation of } 2 \text { or more } \\
\text { variables; comparing, } \\
\text { contrasting, relating variables } \\
\text { in the context of problem. }\end{array}$ & $\begin{array}{l}\text { 4a Trends: determine multiple } \\
\text { types of trends including linear, } \\
\text { power, and exponential trends; } \\
\text { recognize and provide } \\
\text { quantitative explanations of } \\
\text { trends in model representation } \\
\text { within context of problem. }\end{array}$ & $\begin{array}{l}\text { 4a Create Model: ability to } \\
\text { create a model representing } \\
\text { a context and apply it within } \\
\text { context; use variety of } \\
\text { quantitative methods to } \\
\text { construct model including } \\
\text { least squares, linearization, } \\
\text { normal distribution, } \\
\text { logarithmic, logistic growth, } \\
\text { multivariate, simulation } \\
\text { models. }\end{array}$ \\
\hline & $\begin{array}{l}\text { 4b Quantitative Literacy: } \\
\text { reasons with quantities to } \\
\text { explain relationships between } \\
\text { variables; proportional } \\
\text { reasoning, numerical } \\
\text { reasoning; extend to algebraic } \\
\text { and higher math reasoning } \\
\text { (MAA). }\end{array}$ & $\begin{array}{l}\text { 4b Predictions: makes } \\
\text { predictions using covariation } \\
\text { and provides a quantitative } \\
\text { account which is applied within } \\
\text { context of problem. }\end{array}$ & $\begin{array}{l}\text { 4b Refine Model: extend } \\
\text { model to new situation; test } \\
\text { and refine a model for } \\
\text { internal consistency and } \\
\text { coherence to evaluate } \\
\text { scientific evidence, } \\
\text { explanations, and results } \\
\text { (Duschl). }\end{array}$ \\
\hline
\end{tabular}


4c Context: situative view of QR within a community of practice (Shavelson); solves illdefined problems in sociopolitical contexts using ad-hoc methods; informal reasoning within science context (Steen \& Madison; Sadler \& Zeidler).

4d Variable: mental construct for object within context including both attributes and measure (Thompson); capacity to communicate quantitative account of solution, decision, course of action within context.

\begin{tabular}{ll}
\hline Level AL3 & 3a Variation: recognizes \\
Elements & correlation between two \\
& variables without assuming \\
& causation, but provides a \\
& qualitative or isolated case \\
& account; lacks covariation.
\end{tabular}

3b Quantitative Literacy: manipulates quantities to discover relationships; applies measure, numeracy, proportions, descriptive statistics.

3c Context: display confidence with and cultural appreciation of mathematics within context; practical computation skills within context (Steen); lacks situative view.

3d Variable: object within context is conceptualized so that the object has attributes, but weak measure (Thompson); capacity to communicate qualitative account of solution, decision, course of action within context, but weak quantitative account.

\section{Level AL2 2a Variation: sees}

Elements dependence in relationship
between two variables, provides only a qualitative account; lacks correlation, erroneously assumes causation.

2b Quantitative Literacy: poor arithmetic ability interferes with manipulation of variables; struggle to compare or operate with variables. 4c Translation: translates between models; challenges quantitative variation between models as estimates or due to measurement error; identifies best model representing a context.

4d Revision: revise models theoretically without data, evaluate competing models for possible combination (Schwarz). 4c Model Reasoning: construct and use models spontaneously to assist own thinking, predict behavior in real-world, generate new questions about phenomena (Schwarz).

4d Statistical: conduct statistical inference to test hypothesis (Duschl).

\section{3a Trends: recognize difference between linear vs. curvilinear growth; discuss both variables, providing a quantitative account. \\ 3a Create Model: create models for covariation situations that lack quantitative accounts; struggle to apply model within context or provide quantitative account}

3b Predictions: makes predictions based on two variables, but relies on qualitative account; uses correlation but not covariation. qualitative accounts for differences.

3c Translation: attempts to translate between models but struggles with comparison of quantitative elements; questions quantitative differences between models but provides erroneous.

3d Revision: revise model to better fit evidence and improve explanatory power (Schwarz). 3b Refine Model: extend model based on supposition about data; do not fully verify fit to new situation.

\section{3c Model Reasoning}

construct and use multiple models to explain phenomena, view models as tools supporting thinking, consider alternatives in constructing models (Schwarz)

3d Statistical: use descriptive statistics for central tendency and variation; make informal comparisons to address hypothesis. 2a Trends: identify and explain single case in model; recognize increasing/ decreasing trends but rely on qualitative account or change in only one variable.

\section{2b Predictions: makes} predictions for models based on only one variable, provides only qualitative arguments supporting prediction.

\section{2a Create Model:}

constructs a table or data plot to organize two dimensional data; create visual models to represent single variable data, such as statistical displays (pie charts, histograms).

2b Refine Model: extends a given model to account for dynamic change in model parameters; provides only a qualitative account. 
2c Context: lack confidence with or cultural appreciation of math within context; practical computation skills are not related to context.

2d Variable: object within context is identified, but not fully conceptualized with attributes that are measurable; fails to communicate solution, decision, course of action within context; qualitative account without quantitative elements (Thompson). 2c Translation: indicate preference for one model over another but do not translate between models; acknowledge quantitative differences in models but do not compare.

2d Revision: revise model based on authority rather than evidence, modify to improve clarity not explanatory power (Schwarz). 2c Model Reasoning: construct and use model to explain phenomena, means of communication rather than support for own thinking (Schwarz).

2d Statistical: calculates descriptive statistics for central tendency and variation but does not use to make informal comparisons to address hypothesis.

\begin{tabular}{|c|c|}
\hline \multirow[t]{2}{*}{$\begin{array}{l}\text { Level AL1 } \\
\text { Elements } \\
\text { (Lower } \\
\text { Anchor) }\end{array}$} & $\begin{array}{l}\text { 1a Variation: does not } \\
\text { compare variables; works witl } \\
\text { only one variable when } \\
\text { discussing trends. }\end{array}$ \\
\hline & $\begin{array}{l}\text { 1b Quantitative Literacy: } \\
\text { fails to manipulate and } \\
\text { calculate with variables to } \\
\text { answer questions of change, } \\
\text { discover patterns, and draw } \\
\text { conclusions. }\end{array}$ \\
\hline
\end{tabular}

1c Context: does not relate quantities to context or exhibit computational skills.

1d Variable: fail to relate model to context by identifying objects no attempt to conceptualize attributes that are measurable; discourse is forcedynamic; avoids quantitative account, provides weak qualitative account.

Note: MAA, Duschl, Sadler and Zeidler, Schwarz, and Thompson refer to citations of work completed on the QR elements by experts in their fields.

\section{Elements of the QA Progress Variable}

In the third iteration of the QR learning progression Quantification Act (QA) elements were reduced from five to four. We retained (a) Variation, (b) Quantitative Literacy, and (c) Context, but combined Communication with Variable, thereby extending (d) Variable to the fourth achievement level.

The QR team found the ability of students to communicate using a quantitative account was inherent in identifying variables within a context. Thompson's conception of quantification (Thompson 2011) is foundational to the Variable element (Table 2, Progress Variable QA, Elements 1d, 2d, 3d, and 4d). Quantification includes the ability of students to extract quantitative objects from 
a science context, allowing them to move from a qualitative account to a quantitative account. In order to comprehend the object, the student must conceptualize it by determining important attributes of the object and a measure for the object. While Thompson states that measure does not require measuring, but simply the concept of being measureable, the QR team found that quantification in a science context is heavily dependent on the process of measurement. This is inherent in the Nature of Science (NOS) (Lederman 2007). Therefore the Variable element includes determining how the object is measured and what unit of measure is appropriate. Quantification of the context results in variables with attributes and measure which can be compared and contrasted with other variables, and even combined to make new variables. This provides students with the skills to communicate using a quantitative account of the context, opening the pathway for exploring, finding solutions, and determining a course of action within the context.

Interview data provided evidence for the four achievement levels for the Variable element. At AL1 (i.e., QA-1d in Table 2) students make no attempt to quantify variables in the context and often provide even a weak qualitative account. Students rely on a force-dynamic discourse, which includes ways of thinking driven by what they acquire through personal experiences and from authority figures (Mohan et al. 2009). They explain events in the context in terms of actors and enablers: events are caused by actors in accord with their abilities (humans have more ability than animals); actors have needs; the results of events are generally the fulfillment of the actors' needs; events or actions in the world take place when actors have all their needs met; settings must fulfill the needs of the actors for things to happen. At AL2 (QA-2d), students identify quantitative objects within the context and may even assign a variable label such as the letter $x$ to the object, but they fail to determine attributes or measure for the object. Without these, the students are unable to communicate quantitatively about the relationship between variables. They provide a qualitative account of the context, but not a quantitative account. AL3 (QA-3d) is attained when students conceptualize the variable with attributes but still have a weak measure conception. This allows them to provide a clear qualitative account where they explicate the relationship between variables in the context, but the lack of measure hinders the development of establishing quantitative relationships that lead to equations or models. Students are also unable to truly understand the science content inherent to the contextual situation in which the QR is embedded. This deficiency impacts science knowledge as well as application to QM. AL4 (QA-4d) is achieved when students can fully quantify the objects with both attributes and measure, allowing them to construct quantitative accounts of the relationship between variables. This aids students in moving from a forcedynamic discourse to a scientific discourse where fundamental principles govern 
the working system and there is a hierarchy of dynamic systems at different scales (Mohan et al. 2009).

The QA Context element (Table 2, Progress Variable QA, Elements 1c, 2c, 3c, and 4c) did not change from iteration 2 to iteration 3 of the QR learning progression. Student data supported the four achievement levels for context laid out in iteration 2. At AL1 (QA-1c), students failed to relate quantities within the context and often avoided use of quantitative data provided to them. This failure may be due to a lack of confidence in their computational skills. AL2 (QA-2c) finds the students acknowledging quantitative information, but they either lack the confidence with or cultural appreciation of using mathematics within the context. AL3 (QA-3c) is what Madison and Steen (2003) refer to as a display of confidence with and cultural appreciation of mathematics within context. The student quantifies the context without being prompted by the interviewer and exhibits computational skill. AL4 (QA-4c) requires the students to take on a situative view of quantification within a community of practice (Shavelson 2008). A situative view is when the student solves ill-defined problems, addressing social-political contexts inherent in the problem. The student's computational skill includes using ad-hoc methods and informal reasoning to make sense of the context. No students interviewed were ranked at AL4 for the Context element.

The Quantitative Literacy (QL) element (Table 2, Progress Variable QA, Elements 1b, 2b, 3b, and 4b) was adjusted for the third iteration of the QR learning progression by removing the distinction between ability of the student to work with one variable versus two variables. The QR team found that the environmental science contexts predominantly called for comparing two variables and there was little difference observed in students' ability to work with one versus two variables, so the one-variable criterion was removed from the third iteration learning progression. The AL1 for QL (QA-1b) is avoidance or inability to use arithmetic procedures to manipulate and calculate with variables. Students at AL1 did not display the ability to answer questions of change, discern patterns, or draw conclusions. At AL2 (QA-2b), the students attempted to manipulate variables to address a quantitative question, but poor arithmetic ability impeded their progress. AL3 (QA-3b) was populated by students with good arithmetic and computational abilities who could apply them to discover relationships. These students showed evidence of the ability to measure, had strong numeracy skills, used proportions to solve problems, and could apply basic descriptive statistics. AL4 (QA-4b) requires students to demonstrate moving beyond computational skills to reasoning with quantities to provide quantitative accounts of the relationships between variables. The Mathematics Association of America (MAA) calls for students to apply proportional reasoning (PR), numerical reasoning, algebraic reasoning, and extend to higher-level mathematical reasoning. Many students we interviewed struggled with PR within a science 
context. Proportional reasoning is also necessary in understanding science mechanisms that occur at different scales (Jones et al. 2007). For example Taylor and Jones (2008) have discovered that students who have strong PR skills are able to understand surface-area-to-volume concepts essential for learning and understanding science concepts at both the macro and micro scales. This marriage of science knowledge and QR skills is necessary for students to negotiate different contextual situations and create a course of action to solve them.

The Variation element (Table 2, Progress Variable QA, Elements 1a, 2a, 3a, and $4 \mathrm{a}$ ) of QA also remained relatively unchanged between iteration 2 and 3 of the QR learning progression. The inclusion of variation as an element of QA was strongly influenced by the work of Thompson (2011). An understanding of variation in a variable and covariation between two or more variables is foundational to students' ability to interpret a model (QI) or build their own models (QM). At AL1 (QA-1a), we found students who did not believe variables could be compared or avoided making comparisons. They struggled with discussing variation within a single variable. When discussing trends, they would focus on only one variable, even though two variables were being compared. AL2 (QA-2a) consisted of students who recognized a relationship between two variables, but provided only a qualitative account of the relationship. They mistakenly attributed causation to any relationship, not understanding that variables can be correlated without one directly causing the other to change. At AL3 (QA-3a) were students who understood correlation between two variables without assuming causation. However, the students were able to discuss the correlation through only a selected case or data point. They did not have a robust understanding of covariation between two variables. AL4 (QA-4a) requires students to exhibit covariational reasoning to compare, contrast, determine trends, and relate variables within the science context. This finding is in agreement with previous work by Thompson (2011), Johnson (2012), and Castillo-Garsow (2012), who found that students' understanding of covariation is often fragmented and weak.

\section{Elements of the QI Progress Variable}

The Quantitative Interpretation (QI) elements for iteration 3 of the QR learning progression were reduced from six to four. The Authority element from iteration 2 was folded into the (d) Revision element at all four levels. Work by Schwarz et al. (2009) indicated that student reliance on authority could be considered as a characteristic of when a student determined if a model should be revised. The Interpret element from iteration 2 was distributed across the four elements of (a) Trends, (b) Predictions, (c) Translation, and (d) Revision. Coding of student interviews indicated an overlap between Interpret as an element and these four elements. This was in line with the QR team's goal of removing elements that 
were not defined across all four achievement levels. The four resulting elements of Trends, Predictions, Translation, and Revision for iteration 3 were supported as being viable by the student interviews. The Revision element was also supported by Schwarz's work on modeling in science (Schwarz et al. 2009).

The Trends element (Table 2, Progress Variable QI, Elements 1a, 2a, 3a, and 4a) of QI was not significantly revised for iteration 3 of the QR learning progression. Student interviews indicated that at AL1 (QI-1a), students avoided identifying trends. At AL2 (QI-2a), students could select a single case or point on a graph and explain it within context. They would indicate that a model had an increasing or decreasing overall trend, but their quantitative account included only one variable. AL3 (QI-3a) students could go beyond increasing/decreasing trends, to determine if the trend was linear or curvilinear (nonlinear trend) and could provide a quantitative account in which the variation in both variables was discussed. AL4 (QI-4a) requires students to expand their collection of trends beyond linear to include power and exponential trends. Few students were able to identify function models for nonlinear trends or apply nonlinear trends within context to provide a quantitative account.

The Predictions element (Table 2, Progress Variable QI, Elements 1b, 2b, 3b, and $4 \mathrm{~b}$ ) of QI was altered for iteration 3 on AL3. Student interviews were not supporting the inclusion of one categorical variable at AL3 and one-variable predictions at AL2, so AL3 was rewritten to focus on use of correlation but not covariation. AL1 (QI-1b) is the avoidance of making predictions. Students would state that it was not possible to make a prediction outside of the data provided in the model. AL2 (QI-2b) included students who would make a prediction, but base it on only one variable. These students did not account for the second variable, leading to largely qualitative accounts supporting their prediction. AL3 (QI-3b) students provided a prediction based on two variables, including correlation discussions. Their accounts were still more qualitative then quantitative due to a lack of discussion of covariation. AL4 (QI-4b) students were able to provide a quantitative account including covariation applied within the context.

The Translation element (Table 2, Progress Variable QI, Elements 1c, 2c, 3c, and 4c) of QI was revised to provide more detail concerning comparing models. AL1 (QI-1c) students failed to acknowledge that two models can represent the same context. They believed there was one unique or best model for a context. AL2 (QI-2c) included students who acknowledged there could be more than one model for the same context, but they indicated a preference for a given model and refused to translate between this model and others. These students also recognized quantitative differences between two different models, but would not make a comparison of the differences. AL3 (QI-3c) students would attempt to translate between two models, but struggled with developing a quantitative account of how to translate. This difficulty often led to erroneous qualitative accounts of why 
models differed. AL4 (QI-4c) students could not only translate between models for a context, but challenged quantitative variation between models. Students at AL4 discussed how estimates for a variable in the two models could differ or that there could be the introduction of bias into a model to support a desired point of view. AL4 students could select a best model from those provided based not on authority of those creating the model, but on a quantitative account of differences.

The Revision element (Table 2, Progress Variable QI, Elements 1d, 2d, 3d, and 4d) of QI was not altered from iteration 2 to iteration 3. Revision is based on research by Schwarz et al. (2009), assuming much of what had been the Authority element from iteration 2. AL1 (QI-1d) includes students who view models as fixed. These students view models as developed by an authority and believe the models should not be adapted based on new data. The most that students at this level will do is test the model to see if it is a good or bad fit to the data. AL2 (QI2d) students see models as representations that can be revised; however, they revise based on authority rather than evidence. These students will modify a model to improve clarity or fit to data, but not to improve explanatory power of the model. At AL3 (QI-3d), students move to revising a model to both better fit data and improve explanatory power. AL4 (QI-4d) students revise models theoretically without focusing on existing or new data. They evaluate competing models for a context for possible combination. Data from the interviews indicated that the students were functioning at AL1, AL2, and AL3, but AL4 was not achieved.

\section{Elements of the QM Progress Variable}

The elements for Quantitative Modeling (QM) were reduced from iteration 2 to iteration 3 by eliminating the Methods element. The Methods element focused on a student's development of a toolkit of modeling methods, such as least squares, linearization, normal distribution, logarithmic scale, logistic growth, multivariate statistics, and simulations. Student interviews indicated that students had little knowledge of any of these methods, so they were removed from the learning progression as a separate element and folded into the Create Model element. This finding does indicate an area of concern with respect to modeling, but the QR research was focused on current QR abilities, not on development of modeling strategies. Some characteristics of the Methods element are still present in the Create Model element of the revised QR learning progression. The four remaining QM elements are supported by research and current science standards (Duschl et al. 2007; Schwarz et al. 2009).

The QM progress variable is the most undeveloped of the three progress variables due to the difficulty of collecting data on the modeling process. It is difficult to provide students time to develop their own models in an interview 
restricted to 30 to 40 minutes. The discussion below is based on the literature and research, but limited data on QM collected by the QR team.

The Statistical element (Table 2, Progress Variable QM, Elements 1d, 2d, 3d, and 4d) of QM supports the need for students to test and refine models, not just create them. At AL1 (QM-1d), we found students who struggle to use even simple descriptive statistics, such as finding measures of central tendency (mean, median, mode) and spread (range, variance, standard deviation). At AL2 (QM-2d), students calculate these measures, but fail to use them to make even informal comparisons to address a hypothesis about their model. AL3 (QM-3d) students are expected to use central tendency and spread to make informal comparisons of hypothesis, whereas at AL4 (QM-4d) students should be able to conduct statistical inference tests on hypotheses about the models they create.

Duschl et al. (2007) stress the need for students to refine their models to establish internal consistency and coherence so they can evaluate scientific evidence, provide explanations, and provide evidence-based results. The Refine element (Table 2, Progress Variable QI, Elements 1b, 2b, 3b, and 4b) is similar to Schwarz's Revision element, but we make a distinction. The QR team included Revision as an element of QI based on the work of Schwarz et al. (2009). However, we included Refine as an element of QM. The Revision element of QI and Refine element of QM relate to the grey area between updating a model that one is given versus building a substantially new model based on an existing one. The QR team defines revision as changing a model by varying existing variables in the model, but not introducing new variables. Thus Revision is an element of QI since it is an interpretation of existing variables. Refining a model requires the student to remove or insert new variables into an existing model, resulting in a new model accounting for new phenomena. The model is extended to a new situation or context. The QR team considers such activity the construction of a model and so it is included as an element of QM.

AL1 (QM-1b) of the Refine Model element identifies students who accept the authority of a model and so do not see a reason to refine it. AL2 (QM-2b) students believe models can be refined, but restrict themselves to extending the model to account for dynamic change in a model parameter. For example, they may remove a variable from the model to see the impact on predicting events. Students at AL2 provide only qualitative accounts of the change in the model; they do not actually create a new model. AL3 (QM-3b) students extend a model based on suppositions about data, including considering adding new variables to the model. They do not, however, verify the fit of the new model to the new situation. AL4 (QM-4b) students extend the model to a new situation, testing and refining the model for internal consistency and coherence.

The Refine Model element of QM is at the border of interpretation and modeling. The Create Model element (Table 2, Progress Variable QI, Elements 
1a, 2a, 3a, and 4a) is the ability to develop a model directly from data within a context. The Create Model element was significantly changed between iteration 2 and iteration 3 of the QR learning progression, both to clarify the achievement levels and incorporate increasingly sophisticated modeling methods. AL1 (QM1a) includes students who do not view science as model building and refining, so they do not attempt to construct models without prompting, which was observed in interviews. They view science from a forced-dynamic perspective and expect to receive models from experts. AL2 (QM-2a) students accept model building as a process used in science, but have limited model-building tools. They will construct tables and data plots to organize two-dimensional data and are able to create visual statistical displays to represent single-variable data, such as pie charts or histograms. At AL3 (QM-3a), the students advance to creating models that account for covariation between two variables, such as simple linear models, but provide weak quantitative accounts of the models. They find it difficult to apply the model within the context to determine trends or make predictions (QI aspects of using a model). AL4 (QM-4a) students should be able to create a model representing a context and apply it within the context to determine trends and make predictions. They should have a variety of quantitative modeling strategies, such as least squares, linearization, normal distribution, logarithmic scale, logistic growth, multivariate statistics, and simulations.

The fourth element of QM is Model Reasoning (Table 2, Progress Variable QI, Elements 1c, 2c, 3c, and 4c) and is based once again on the work of Schwarz et al. (2009). There was no change in the Model Reasoning element between iteration 2 and iteration 3 of the QR learning progression. According to Schwarz, at AL1 (QM-1c), students construct and use models that are literal illustrations. The Create Model element states that students must be prompted to build models. The result for Model Reasoning is that students see models as an organization of data for display. A model is a demonstration for others, but is not used by the student as a tool to generate new knowledge. AL2 (QM-2c) students construct simple models without prompting, using the model to explain a phenomenon to others. The students use the model as a means of communicating outcomes to others, but not as a support for their own thinking. AL3 (QM-3c) students may construct multiple models for the same context to explain phenomena and consider alternatives in constructing models. They view models as tools supporting thinking, not just as convenient displays of data. The Create Model element indicates that while students may have moved up a level in model reasoning, they still struggle with providing rich quantitative accounts of their models. For Model Reasoning at AL4 (QM-4c), students should be able to construct and use models spontaneously to assist their own thinking, predict behavior in the real-world, and generate new questions about the phenomena. 
These abilities come hand-in-hand with a richer knowledge of multiple methods which are part of the Create Model element.

\section{Discussion and Conclusion}

The current QR learning progression reflects the QR team's most up-to-date understanding of the trajectory of student development of quantitative reasoning within the context of environmental science. These understandings are based on research literature related to $\mathrm{QR}$ and the analysis of student qualitative data. However, the development of learning progressions is an iterative cycle of testing the proposed progression. The QR team is still in the beginning stages of this cycle, and there is a lot of work to be done to verify the proposed learning progression.

The next step, which has already begun, is to move from interviews to a closed-form assessment, which can be administered to a large sample of student participants at sites across the country. Due to the intensive nature of creating such assessments, the QR team has decided to focus on only one of the three QR progress variables at a time. QI has been selected as the focus of the first closedform assessments to adhere to the Pathways Project's goal of developing environmentally literate citizens. On a day-to-day basis, citizens may be provided models by science experts and asked to make decisions that could impact local, regional or even global communities. In order to make an informed decision it is imperative that environmentally literate citizens be able to interpret these models, rather than build their own models using misinformation or even science misconceptions.

In Spring 2013, three closed-form QI assessments were developed, one for each of the science strands in the Pathways Project: QI Carbon, QI Water, and QI Biodiversity. These assessments were taken by over 500 students in three states, and the data are currently being analyzed using Rasch Modeling (Bond and Fox 2007; de Ayala 2009). This analysis will provide important data both for revising the learning progression and the closed-form assessments, as well as ultimately informing educators and researchers on the state of QR in environmental science.

What are the next steps in developing the learning progression? Once revisions of the QI closed-form assessments based on Rasch Modeling are completed, the QR team plans to conduct a large national survey of QI ability using the quantitative assessment instrument and conducting structured interviews with a stratified random sample of participants. This will provide additional data to revise the learning progression for the QI progress variable. A similar effort needs to be undertaken for the QA and QM progress variables. Once the QR learning progression is sufficiently verified and the assessments are confirmed as 
reliable and valid, then the development of teaching experiments for $\mathrm{QR}$ in environmental science can be developed. The Pathways Project has already developed teaching experiments for the Water Strand, Carbon Strand, and Biodiversity Strand, which incorporate some QR. The objective is to develop QRenriched teaching experiments that can be used both for professional development of STEM teachers and as performance tasks in science and mathematics classrooms. The goal is to increase the QR ability of students and thus create more environmentally literate citizens.

\section{Acknowledgments}

This project is supported in part by a grant from the NSF: Culturally Relevant Ecology, Learning Progressions, and Environmental Literacy (DUE-0832173).

\section{References}

AAC\&U (American Association of Colleges and Universities). 2010. VALUE: Valid Assessment of Learning in Undergraduate Education.

http://www.aacu.org/value/rubrics/index_p.cfm

Bond, T. G., and C. M. Fox. 2007. Applying the Rasch model: Fundamental measurement in the human sciences, 2nd ed. Mahwah, NJ: Lawrence Erlbaum.

Castillo-Garsow, C. 2012. Continuous quantitative reasoning. In WISDOMe: Quantitative reasoning and mathematical modeling: A driver for STEM integrated education and teaching in context, eds. R. Mayes and L. Hatfield, 55-74. Laramie, WY: University of Wyoming.

Charmaz, K., 2006. Constructing Grounded Theory: A Practical Guide Through Qualitative Analysis. Thousand Oaks, CA: Sage.

Corbin, J., and A. Strauss. 2008. Basics of Qualitative Research. Los Angeles: Sage Publications.

Corcoran, T., F. A. Mosher, and A. Rogat. 2009. Learning progressions in science: An evidence-based aproach to reform. Philadelphia, PA: Consortium Policy Research in Education.

de Ayala, R. J. 2009. The theory and practice of item response theory. New York, NY: The Guildford Press.

Duschl, R.A., H. A.Schweingruber, and A. W. Shouse. 2007. Taking science to school: Learning and teaching science in grades K-8. Washington, DC: National Academies Press.

Johnson, J. L. 2012. Reasoning about quantities involved in rate of change as varying simultaneously and independently. In WISDOMe: Quantitative reasoning and mathematical modeling: A driver for STEM integrated education and teaching in context, eds. R. Mayes and L. Hatfield, 39-54. Laramie, WY: University of Wyoming.

Jones, M.G., A. Taylor, J. Minogue, B. Broadwell, E. Wiebe, and G. Carter. 2007. Understanding scale: Powers of ten. Journal of Science Education and Technology Education 16(2): 191-202. http://dx.doi.org/10.1007/s10956-006-9034-2 
Lederman, N. G. 2007. Nature of science: Past, present, and future. In Handbook of Research in Science Education, eds. S.K. Abell and N.G. Lederman, 831-880. Mahwah, New Jersey: Lawrence Erlbaum Publishers.

Madison, B.L. and L.A. Steen, eds. 2003. Quantitative literacy: Why numeracy matters for schools and colleges. Princeton, NJ: National Council on Education and the Disciplines.

Mayes, R., F.I. Peterson, and R. Bonilla. 2013a. Quantitative reasoning learning progressions for environmental science: Developing a framework. Numeracy 6(1): Article 4. http://dx.doi.org/10.5038/1936-4660.6.1.4

Mayes, R.L., J.H. Forrester, J. S. Christus, F.I. Peterson, R. Bonilla, and N. Yestness. 2013b. Quantitative reasoning in environmental science: A learning progression. International Journal of Science Education. http://dx.doi.org/10.1080/09500693.2013.819534

Mohan, L., Chen, J., and Anderson, C.W. (2009). Developing a multi-year learning progression for carbon cycling in socio-ecological systems. Journal of Research in Science Teaching, 46: 675-698. http://dx.doi.org/10.1002/tea.20314

Schwarz, C.V., B.J. Reiser, E. A. Davis, L. Kenyon, A. Archer, D. Fortus, Y. Shwartz, B. Hug, and J. Krajcik. 2009. Developing a learning progression for scientific modeling: Making scientific modeling accessible and meaningful for learners. Journal of Research in Science Teaching 46: 632-654. http://dx.doi.org/10.1002/tea.20311

Shavelson, R. 2008. Reflections on quantitative reasoning: An assessment perspective. In Calculation vs. context: Quantitative literacy and its implications for teacher education, eds. B. L. Madison, and L. A. Steen, 22-47. Washington, DC: Mathematical Association of America.

Steen, L. A., (exec. ed.) 2001. Mathematics and democracy: The case for quantitative literacy. The Woodrow Wilson National Fellowship Foundation, The National Council on Education and the Disciplines.

Taylor, A., and M. G. Jones. 2008. Proportional reasoning ability and concepts of scale: Surface area to volume relationships in science. International Journal of Science Education 31: 1231-1247. http://dx.doi.org/10.1080/09500690802017545

Thompson, P.W. 2011. Quantitative reasoning and mathematical modeling. In New perspectives and directions for collaborative research in mathematics education, eds. L. L. Hatfield, S. Chamberlain, and S. Belbase, 33-57. Laramie, WY: University of Wyoming. 